\title{
Learning Discourse Analysis by Applying Metaphorically-Based Materials
}

\author{
Amrin Saragih ${ }^{1}$, Anggraini T Saragih ${ }^{1}$, Muhammad Natsir ${ }^{1}$, Fauziah Khairani Lubis ${ }^{1}$ \\ ${ }^{1}$ English Department, Faculty of Languages and Arts, State University of Medan (Unimed), Indonesia
}

\begin{abstract}
:
The objective of the study is to investigate the effect of learning Discourse Analysis (DA) by applying metaphorically-based materials. Both the design of qualitative and quantitative study is applied in the present study with 60 student subjects of English Literature Study Program ofthe Faculty of Languages and Arts Universitas Negeri Medan, Indonesia. The subjects were divided into two groups: Experimental and Control Group, each with 30 sudents which is parallel in terms of level of intellectuality and learning facilities. The Control Group studentswere taught the lecture of DA by applying conventional material and model of learning or lecturing whereas the Experimental Group were taught by applying metaphorically-based materials of DA. The students' achievements were obtained by administering the test and the scores of the two groups were compared and processed by applying $t$-test at the significance level of $\alpha=0.05$ with two-tailed test. It is found that the $t$-obs value is 2.764 exceeding or being greater than that of the $t$-tab value of $2.00(2.764>2.000)$ where the Ho is rejected implying that the $\mathrm{Ha}$ is accepted verifying that learning the lecture of DA is significantly more effective by using metaphorically-based materials than by applying conventional materials or lecturing.
\end{abstract}

Keywords :

learning; discourse analysis; metaphorically-based material

\section{Introduction}

Metaphor refers to the shift of unmarked coding of experience to that of marked one. By its characteristics, metaphor involves a comparison as such that an abstract experience is converted into a concrete one. There have been nomurous studies of metaphhor, such as that of Danesi (2013: 189) concluding that metaphor function to turn abstract experience to concrete one, Coleman and Kay (2000: 49) claiming metaphor functioning to change sensory experience to cognitive ones, Griffiths (2006: 88) asserting metaphorizing one's personalities to others, Halliday and Matthiessen (2006: 227) and Halliday (2014: 29) stating congruent experience potentially converted to incongruent ones. However, none of the studies have dealt with the use of metahorically-based materials in learning DA nor have the findings been applied in teaching or leaning DA. This article specifically treats the use of metaphorically developed materials in teaching or learning DA lecture. Despite its limitations, the present study has resulted a new finding which enriches horizons or theories in applied linguistticc

\section{Methodology}

A qualitative research design (in developing metaphorically-based materials of DA lecture) and quantiative (in testing the hypothesis by applying t-test) one were used in this study. The subjects of the study were 60 students of the English Literaturre Study Program, the Faculty of Languages and Arts Universitas Negeri Medan. The subjects were divided into Experimental Group (X) and Control Group (Y), each with 30 students and one is parallel to the other in terms of itellectuality and learning facilities. The Experimental Group was taught by using the metaphorically-based material whereas the Control group was taught by using conventional 
materials of DA with lecturing model. After referring to previous theories of metaphor and relevan studies, the null and alternative hypothesis are put forwards as the following.

Ho: There is no significant difference between the students' scores taught by using metaphoricallybased materials in DA lecture and those by appying conventional materials or model of learning. Ha: There is a significant difference between the students' scores taught by using metaphoricallybased materials in DA lecture and those by appying conventional materials or model of learning.

The procedures taken follow the ensuing steps. Firstly, metaphorically-based materials of DA lecture are designed and developed. At this stage qualitative reseach design was applied. The materials are made available by considering the following elements: what were going on in classroom activities, facilities used, cultural aspects, customs and traditions performed in the classroom. The theories underlying this study is those of systemic functional linguistics (SFL) as developed by Halliday (2014), Halliday and Matthiessen (2006), Martin (1992) and other systemicists. By referring to theories of metaphor and realting to the social contexts of the students, metaphorically-based materials of DA were constructed. Some of the metaphorical materials of DA are discourse and text are head and tail of coin, experiential function is ingrediants of cooking, interpersonal function is the way of cooking, textual function is the manner of serving the meals, logical function is relations of one menu to another and cohesion is a thread of meaning in the text. Secondly, teaching of DA by applying metaphorically-based material in the Experimental Group and that by applying conventional materials or model of learning in the Control Group were done. Before and after the treatments, the students of the two groups were tested resulting pretest and postest scores wwhich were needed in applying the statistic test of t-test. At the third stage the scores obtained by the students of both the Experimental and Control groups were processed statistically. The statistics of t-test were applied to test the null hypothesis at the level of significance $\square=0.05$ with two-tailed test.

\section{Findings and Discussions}

\subsection{Findings}

It is found that the mean score of the students in Experimental Group (80.8) is significantly greater than that in the Control Group (67.2). This means that the use of metaphorically-based materials in DA lecture significantly results in a more effective way than that of conventional materials or lecture model of learning. This implies that learning DA by using materially-based materials is effective.

The mean of post-test score of Experiemntal Group is 80.8 and that of Control Group is 67.2. Prior to this the mean of pretest score of Experiemntal Group is 56.6 and that of Control Group is 49.1. The pretest and post-test scores indicate that the treatments result in greater or higher achiement. However, specifically the increase of mean score of the Experimental Group is greater that that of the Control Group. The difference is statistically significant. Applying the ttest formula and statistical procedures it is found that the value of t-count or t-obs is 2.746 and that of $\mathrm{t}$-tab or the critical value is 2.00 with the $\mathrm{df}=58$ at the level of $\square=0.05$ with two-tailed test. As the t-obs value of 2.764 exceeds or is greater than that of the $t$-tab value of 2.00 $(2.764>2.000)$, the Ho is rejected. Further, as the consequence of Ho being rejected is that the $\mathrm{Ha}$ is accepted. Thus, learning DA by using metaphorically-based material is effective.

\subsection{Discussions}

Several points need discussing in relation to the finding of he study. 
(1) Applying metaphorically-based materials is a new trend in learning DA lecture in the sense that such an approach has not been conducted in the literature of teaching or learning DA. There have been various theories of metaphor and findings of studies on metaphor. There have also been models or techniques of learning linguistically related subjects such as lecturing, simulating, problem solving, group discussions etc. However, learning or teaching DA by applying metaphorically-based materials is a new one. Thus, the finding of this study adds up or enriches horison in learning or teaching DA.

(2) There are three reasons supporting the effectiveness of applying metaphorically-based material in learning DA. Firstly, metaphorically-based materials of DA turn abstract concept or theory into concrete thing (Danesi 2013: 189). This facilitates learning. For example, in studying DA the students were taught definition of discourse and text. One of the descriptions says that discourse and text are the same thing wherediscourse treats content and text is concerned with form. This material is hard for the Indonesian students to understand because it is abstract. Only students who have knowledge of semiotics can distinguish the element of content or meaning from form or expression. However, the abstact material can be converted into a concrete one by claiming discourse and text represent the head and tail of a coin. The head of the coin is discourse and the tail is text. In a similar manner, discourse and text can be metaphorized by money, namely a bank note. The text and discourse are analogous to paper andvalue inscribed on the bank note. For example, on a Rp10.000 bank note, the paper money is the text whereas the value of Rp10,000 is the discourse. Learning meaning is the main concern in studying DA. However, as meaning is an abstract thing it is cognitively hard for the students to grasp. By metaphorizing the meaning it is materialized and is looming up tobe concrete and thus, easily learnt by the students. In other words, it can be said that by metaphor approach, the mataphorically-based DA materials can be made concrete or can be indentified by more senses than by conventional DA materials. The more senses are used to identify a phenomenon, the better or clearer the phenomenon becomes. Secondly, metaphor causes tension between wording and meaning or between lexicogrammar and semantics, which results in one's eagerness to learn something. The tension between lexicogrammar and semantics is caused by the shift of unmarked or common coding into the marked or uncommon one. For example,on hearing a metaphorical clause Betty is my star, people get surprised and eager to learn what similarities there exist between a star and Betty. In the same manner the metaphorical expression cohesion is a thread of meaning in the text motivate students to learn what similarities there exist between cohesion and thread as it is commonly known that a thread or yarn is normally related to sewing or kite. The shift from unmarked to marked coding causing eagerness or curiousity involves emotional aspects, sensory and cognitive aspects. In other words, learning through metaphorical expresion involves emotions and cognition or both sensory and cognitive aspects. As metaphorically-designed DA materials challenges cognitive, affective and sensory aspects learning is intensifies. Thirdly, metaphorically-designed materialinduces power of creativity or innovation. In learning the DA metaphorical materials the students constructmeaning on learning. This implies that metaphor is related to constructivism. A metaphor has a power in its potential nuances of meaning. This is to say that a metaphorical expression has numerous shades of meaning and on learning a metaphorical expression at a certain time a student can grasp one meaning from the array of meanings and at another time s/he can take another meaning to make sense of the metaphorical expression. Mottos, yels or icons of communities or associations are expressed in metaphor and the metaphorical expressions are their identities. In understanding the metaphorical expressions of the mottos someone may undertsand them by a certain meaning at a certain time and at another time s/he may understand the mottos by another meaning. To illustrate the case, a metaphorical expression may have an array 
of meaning as $\mathrm{m}_{1}, \mathrm{~m}_{2}, \mathrm{~m}_{3}, \mathrm{~m}_{4} \ldots \mathrm{m}_{\mathrm{n}}$. At a certain time on learning the metaphorical expression a student may take $\mathrm{m}_{1}$ and satisfy himself/herself with the $\mathrm{m}_{1}$ but at another time in the development or evolution of his/her understanting $\mathrm{s} /$ he may take $\mathrm{m}_{2}$ to satisfy himself/herself and so on. For example, in learning the expression of Indonesia isnow developing itself to bethe tiger of Asia or the rooster of Kinantan from Medanis entering the field of metaphors. The tiger of Asia is a metaphor which indicates a powerful country in various aspects, such as economy, politics, sport, science, etc. The rooster of Kinantan is used to refer to soccer team from Medan kown as the PSMS. The soccer team has been metaphorized with rooster where it usuallu wins in rooster fights. The metaphorical expression of the tiger of Asiapotentially indicates the meaning of power, wildderness, savage, carnivorous etc. In a similar manner, the rooster of Kinantan may mean fight, victory, strength, etc. In the same manner in DA lecture textual function indicates the culminative and periodic waves. This metaphorical expression in DA means that the textual function indicates that the message moves like a wave of the sea does where the culminative mopint and the fall can be observed. The terms Theme and Rheme resembles the mannerof the wave movement. With reference to the array of meaning of metaphor it can be stated that the metaphorically-based materials develop one's imaginations and this potentially developes to creativity and innovation.

(3) One of the impacts of learning mataphorically-based DA materials is that the practice induces idea engineering. It has been previously described that metaphorical material simultaneously stimulates affective, cognitive and constructive aspects. Metaphor involves the transfer of meaning of an entity to another due to the similaries between the two entities. By applying metaphorical thinking, one can describe something with reference to something else as there are similar characteristics in a particular way between the two things. The expression of you're my sun is derived as the person concerned is regarded as if $\mathrm{s} / \mathrm{he}$ were the sun that gives light and power in one's life as the sun does in reality. The new worldview derived by metaphorical thinking indicates creativity where a new idea is derived from limited and conventionally known sources by the engineers, technologists and artists. The newly created idea in turn potentially leads to innovation where the new idea is further developed to process, product or service with economically, socially or culturally added values. In this way, metaphorical thinking is a means of enhancing idea engineering. Harris (2014: 97) describes idea engineering as realted to using creative thinking to form a new worldview leading to innovation. In this way, idea engineering is subsumed in creativity and innovation. Thus, metaphor is potentially used to facilitate or to enhance idea engineering.

(4) This study has limitation in two respects, namely in the number of subject and the use of method of teaching or models of learning. Firstly, this study is based on the data collected from 60 university students in the lecture of discourse analysis in Eglish. If the number of the students is greater the conclusion derived potentialy changes. In the same manner, if the method of teching the students or the model of leraning DA involved in this study varies the also potentially changes.

\section{Conclusions}

After analyzing the data and statistically processing the students' achievements in both groups, conclusions are drawn as the following.

(1) Teaching or learning DA in English by applying metaphorical materials is significantly more effective that teaching or learning the DA lecture by using conventional materials or model of learning. Statistical testing by using t-test indicates that the value of t-obs is greater than that of t-table at the significance level of $\square=0.05$ with two-tailed test. This is 
to say specifically that the t-obs value of 2.764 exceeds or greater than that of the t-tab value of $2.00(2.764>2.000)$. Thus, the Ho is rejected and the Ha is accepted.

(2) This study has limitation in the sense that this study is restricted by the number of subjects totalling to 60 students. It is predicted that if more repondents are involved the findings potentially change.

\section{Acknowledgements}

Lecturer Groupsof Related Expertises known as Kelompok Dosen Bidang Keablian (abbrevriated as KDBK) are set up at the English Literature Study Program Universitas Negeri Medan. One of the tasks of the group is to make learning DA effective. This study is aimed at fulfilling the task. The KDBK researcher team realize that this paper will not be complete without assistances given by others.

Firstly, the researchers would like to thank the Dean of the Faculty of Languages and Arts Universitas Neger Medan for providing fund and finnancial supports to conduct thhis study and to bring this article into existance.

Secondly, the reseachers thank the KDBKBM lecture colleagues who have given motivation for doing the study.

Thirdly, the team would like to extend thanks and indebtedness to the Research Institution of the Universitas Negeri Medan that has given helps and administrative assistances in doing this study.

Fourthly, the resaechers than all the 2017/2018 academic year students of the English Literature Study Program who have participated in this study voluntarily.

Finally, thanks, gratitudes, indebtedness and respects are extented to the Language Centre of the North Sumatra Province for all their hepls and assitances in kinds.

It is expecteed that findings of the study as presented in this article would be useful to the lecturers at the Universitas Negeri Medan.

\section{References}

Danesi, M. 2013. Encyclopedia of Media and Communication. Toronto: University of Toronto Press. Griffiths, P. 2006. An Introduction to English Semantics and Pragmatics. Edinburgh: Edinburgh University Press.

Halliday, M.A.K. and C. M. I. M. Matthiessen. 2006. Construing Experience throughMeaning: a Language Based Approach toCognition. London: Continuum

Halliday, M.A.K. (2014). An Introduction to Functional Grammar. edisi keempat London: Routledge..

Harris, La Verne A. 2014. Idea Engineering: Creative Thinking and Innovation. New York: Momentum Press 